\title{
DAMPAK PANDEMI COVID-19 TERHADAP KESEHATAN MENTAL ORANG TUA DAN ANAK
}

\author{
Yafi Sabila Rosyad $^{1^{*}}$, Setya Retno Wulandari ${ }^{2}$, Istichomah ${ }^{1}$, Rika Monika $^{1}$, \\ Anisa Febristi ${ }^{3}$, Dewi Mekar Sari ${ }^{4}$, Ayu Devita Citra Dewi ${ }^{5}$ \\ ${ }^{1}$ Program Studi S1 Keperawatan, STIKes Yogyakarta, \\ ${ }^{2}$ Program Studi D3 Kebinanan, STIKes Yogyakarta \\ ${ }^{3}$ Prodi D3 Keperawatan, Akademi Keperawatan Baiturrahma Padang \\ ${ }^{4}$ Prodi D3 Keperawatan, Akademi Keperawatan Nabila Padang \\ ${ }^{5}$ Sekolah Tinggi Ilmu Kesehatan Bina Husada Palembang \\ *e-mail: Rosyad2yafi@gmail.com
}

\begin{tabular}{|c|c|}
\hline & Abstract \\
\hline $\begin{array}{l}\text { Keywords: } \\
\text { Parental stress, } \\
\text { Child psychology, } \\
\text { COVID-19 } \\
\text { pandemic, } \\
\text { Mental health }\end{array}$ & $\begin{array}{l}\text { Even one year, the COVID-19 pandemic has occurred. One of them has a } \\
\text { significant impact on mental health for parents and children, affects } \\
\text { changes in family function, and raises the risk of the posttraumatic } \\
\text { syndrome. This study aims to find gaps and novelty related to the impact } \\
\text { of the COVID-19 pandemic on the mental health of parents and children. } \\
\text { This study is a literature review was conducted on March } 1 \text { - April } 7 \text {, } \\
2021 \text {, with the PRISMA model flow chart. The researcher uses a publish } \\
\text { or perish application for search article. The search for articles through } \\
\text { the publish or perish application by searching through three databases, } \\
\text { namely crossref, google scholar, and PubMed, obtained } 1216 \text { data in the } \\
\text { form of research articles, books, letters to editors, and review sheets } \\
\text { article. While searching for data through registers, the researcher used a } \\
\text { directly registered record and obtained } 339 \text { data in scientific papers and } \\
\text { letters to editors. The final results were } 15 \text { articles from the } 30 \text { articles } \\
\text { reviewed from the three stages of the database search process. The } \\
\text { methodological review of } 15 \text { articles showed that almost all articles used } \\
\text { the quantitative method, including } 14 \text { articles and } 1 \text { article using the Mix } \\
\text { method. From the assessment of the contents of the research results, there } \\
\text { are three major categories: behavioural changes, emotional and } \\
\text { psychological changes, and health impacts. Of all the articles obtained, } \\
\text { almost all of them use quantitative research, so researchers suggest that } \\
\text { further researchers use qualitative or mixed methods. Researchers } \\
\text { recommend using a quasi-experimental design that aims to overcome and } \\
\text { prevent PTSD from occurring if you want to use the technique. }\end{array}$ \\
\hline
\end{tabular}




\section{PENDAHULUAN}

Setelah wabah COVID-19 menjadi epidemi di Negara Cina, WHO pada tanggal 30 Januari 2020 menyatakan COVID-19 sebagai pandemi Global (WHO, 2020). Setelah pernyataan dari WHO semua Negara menjadikan COVID-19 masalah bencana nasional termasuk Pemerintahan Indonesia. Pemerintahan menyatakan penyakit COVID-19 sebagai Wabah nasional pada bulan Maret 2020 (Kemenkes, 2020b).

Belum berakhirnya pandemic COVID-19 didunia maupun di Indonesia selama lebih dari enam bulan mengkibatkan dampak disegala sektor terutama sektor kesehatan. Untuk memulihkan keadaan pemerintah membuat kebijakan baru yang kita kenal dengan kehidupan new normal. Kebijakan ini diambil untuk mengembalikan kestabilan ekonomi (Kemenkes, 2020a). Selain sektor ekonomi, sektor pendidikanpun terkena dampak. Semua aktifivas pendidikan dilakukan secara online(Makarim, 2020).

Layanan edukatif layanan yang ditujukan untuk anak-anak dari segala usia juga ditutup, serta kegiatan belajar mengajar dari kelas dasar dan seterusnya diberikan secara online. Pembatasan pergerakan diperlakukan untuk seluruh populasi; semua orang dilarang meninggalkan rumah kecuali hal-hal mendesak seperti sakit, berbelanja kebutuhan pokok dan pekerjaan yang tidak bisa dilakukan secara online. Sebagian besar kegiatan ditutup dan banyak orang kehilangan pekerjaan atau mengalami pengurangan pendapatan mereka. Disamping itu semua, sebagai orang tua harus menemani dan membimbing anak mereka untuk melakukan pembelajaran secara online (Spinelli, Lionetti, Pastore, \& Fasolo, 2020).

Kondisi kehidupan keluarga tiba-tiba sangat berubah selama pandemic COVID-19. Di lingkungan rumah, peran orang tua untuk pendidikan anak-anak menjadi lebih penting dari sebelumnya karena dampak pendidikan secara online(Wang, Zhang, Zhao, Zhang, \& Jiang, 2020). Orang tua secara umum melakukan pengelolaan anak-anak mereka dan lingkungan rumah. Banyak orang tua harus bekerja sambil mengasuh anak bahkan membantu anak mereka menyelesaikan pekerjaan rumah yang diberikan guru diwaktu yang bersamaan. Pekerjaan kantor, peran sebagai pendidik karena mengantikan peran guru dan pekerjaan rumah menjadi beban dalam satu waktu yang harus dijalani orang tua selama masa pandemic COVID-19. Situasi ini secara signifikan meningkatkan risiko mengalami stres dan emosi negatif pada orang tua, dengan efek yang berpotensi menurunkan kesejahteraan anak-anak (Sprang \& Silman, 2013).

Sebagian besar penelitian dilakukan selama pandemi sebelumnya dan sejak awal pandemi COVID-19 terkait psikologis pada populasi umum (Brooks et al., 2020; Rias et al., 2020; Sitohang et al., 2020). Salah satu penelitian mengatakan bahwa tingkat stres pasca-trauma pada anak yang mengalami karantikan akan empat kali lebih tinggi daripada anak yang tidak mengalami karantina(Sprang \& Silman, 2013). Sebuah studi pendahuluan dilakukan di China melaporkan adanya kesulitan psikologis pada anak-anak selama pandemi COVID-19, dengan ketakutan, kemelekatan, kurangnya perhatian, dan mudah tersinggung sebagai gejala yang paling parah untuk anak-anak yang lebih kecil(Jiao et al., 2020). Hasil penelitian Spinelli et al. (2020), mengatakan bahwa masa karantina selama pandemic COVID-19 berdampak signifikan terhadap stress orang tua dan emosional pada anak. Pemahaman yang lebih dalam tentang proses keluarga, faktor pelindung, dan faktor risiko di lingkungan rumah mungkin penting untuk dipromosikan di masa-masa sulit ini jika kesejahteraan anak-anak diinginkan(Wang et al., 2020).

Secara umum, baru sedikit yang diketahui tentang faktor-faktor apa saja yang terkait dengan perlindungan terhadap perilaku dan masalah emosional anak dan orang tua selama keadaan pandemic COVID-19. Di Indonesia sendiri belum ada penelitian terkait hal terbut. Oleh sebab itu, peneliti melakukan studi literature review sebagai tahap awal untuk melihat gap dan novelty terkait topic tersebut sebelum melakukan penelitian secara langsung di lapangan.

\section{METODE}

Penelitian ini merupakan penelitian sekunder berjenis literature review. Metode ini merupakan suatu rangkaian penelitian dengan metode pengumpulan data pustaka (buku, ensikopedi, jurnal ilmiah, koran, majalah, dan dokumen) (Denney \& Tewksbubry, 2013;Zed, 2014). Hamzah (2019), mengemukakan bahwa penelitian kepustakaan sangat dekat dengan penelitian kualitatif dengan ciri utama pada bekerja pada tataran analitik bukan statistik yang difokuskan pada cara memperoleh data mengunakan metode wawancara, observasi, dan dokumentasi. Triangulasi dalam konteks penelitian kepustakaan merupakan interaksi peneliti dengan buku atau bahan pustaka sebagai 
bahan interview atau observasi terhadap data sekunder.

Strategi pencarian artikel menggunakan aplikasi publish or perlish yang merupakan aplikasi pencarian database dari Google scholar, Google Sholar Profile, Pubmed, Crossef, Microsoff academic, Scopus, dan Web Of Science. Literature review ini dibatasi dari tahun 2020-2021. Keyword yang dipakai adalah Parent's stress and psyocological children,s during COVID-19 outbreack. Kriteria eksklusi yang digunakan yaitu Publikasi yang bukan merupakan hasil penelitian seperti artikel surat ke editor,buku dan artikel yang abstrak saja. Alur telaah jurnal ini dilakukan sesuai dengan gambar berikut: Penelitian ini dilakukan pada bulan 1 Maret- 7 April 2021 dengan menelusuri artikel di Pubmed, Crossef,Google scholar, dan sciendirect. Peneliti menggunakan Diagram alir model PRISMA untuk menggambarkan aliran informasi melalui berbagai fase tinjauan sistematis. Diagram Ini akan memetakan jumlah data yang diidentifikasi, data yang diambil dan dibuang, dan alasan untuk pengecualian (Page et al., 2021a, 2021b, 2021c). Gambar 1

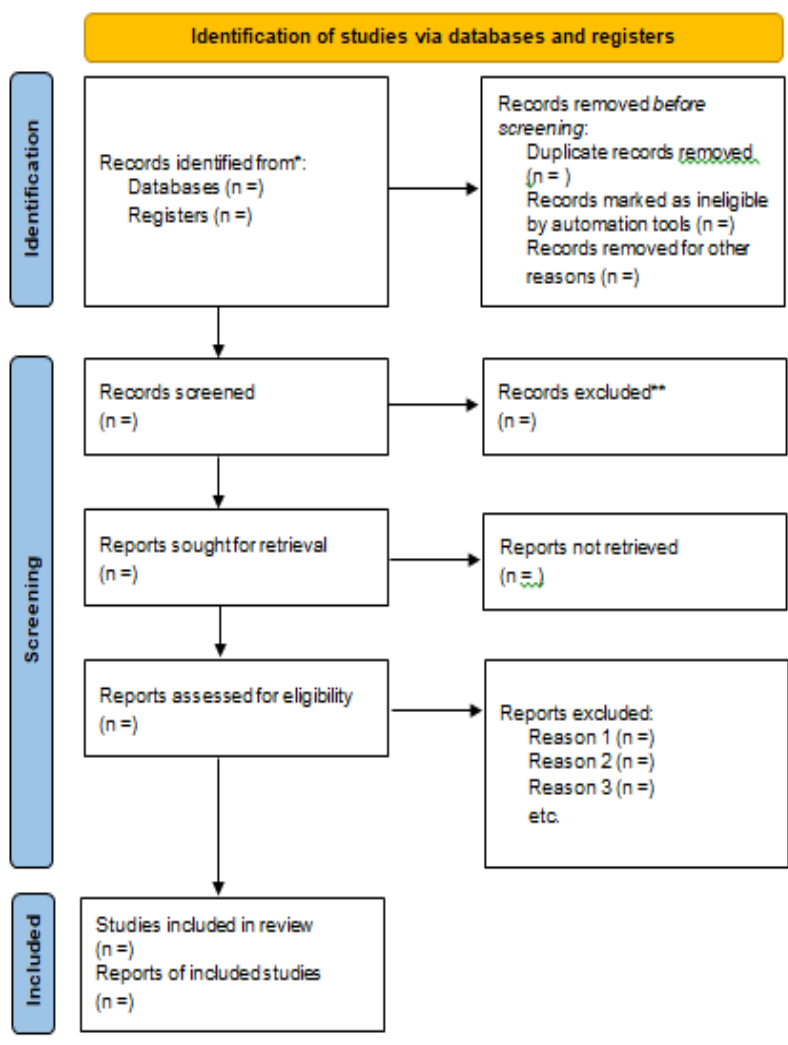

Gambar 1. Diagram PRISMA

\section{HASIL DAN PEMBAHASAN Database}

Hasil penelusuran artikel melalui aplikasi publish or perlish dengan pencarian melalui tiga database yaitu crossef, google scholar, dan pubmed didapatkan 1216 data yang berupa artikel penelitian, buku, surat untuk editor, dan lembar review artikel. Sedangkan, pencarian data melalui registers peneliti menggunakan register sciencedirect dan didapatkan 339 data yang berupa artikel ilmiah, dan surat untuk editor. Dari ketiga tahap proses pencarian data base didapatkan hasil akhir 15 artikel dari 30 arttikel yang direview. Tabel 1

Tabel 1.

Hasil pencarian database dan register

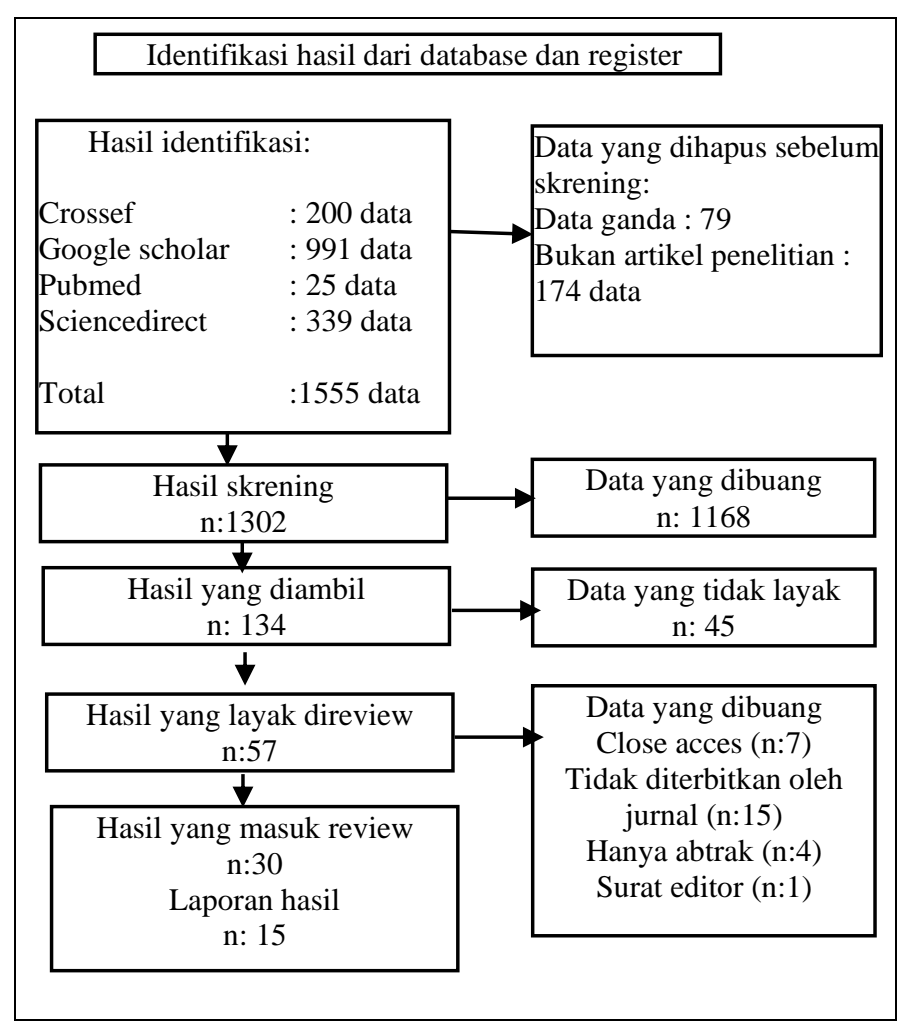

\section{Metodologi}

Hasil review metodologi dari 15 artikel didapatkan hasil hampir seluruh artikel menggunakan metode kuantitatif sejumlah 14 artikel dan 1 artikel dengan metode Mixmetod . Lima artikel menggunakan design penelitian diskriptif statistik (Calvano et al., 2021; Chartier, Delhalle, Baiverlin, \& Blavier, 2021; Cusinato et al., 2020; Gupta \& Jawanda, 2020; Watamura \& Koppels, 2020). Diskriptif statistik merupakan penyajian data dengan gambaran secara umum (Sugiono, 2016). Sembilan artikel menggunakan design cross sectional (Li, Qin, Shi, \& Han, 2021; Ma et al., 2021; Mazza et al., 2021; Morgül, Kallitsoglou, \& Essau, 2020; Moscardino et al., 2021; Orgilés et al., 2021; Romero et al., 2020; Shorer \& Leibovich, 2020; Yue, Zang, Le, \& An, 2020). Desain cross sectional merupakan salah satu design kuantitatif yang berfungsi untuk mencari 
hubungan antar variabel (Creswell, 2016; Sugiono, 2016). Satu artikel dari metode kuantitatif menggunakan design longitudinal. Design longitudinal merupakan pembandingan subjek penelitian pada periode yang berbeda. Metode penelitian mixed method digunakan oleh satu artikel (Masjoudi, Aslani, Khazaeian, \& Fathnezhad-kazemi, 2020). Mixed Method merupakan metode campuran antara metode kuantitatif dan kualitatif. Pada artikel Saurabh \& Ranjan, (2020), peneliti menggunakan explanatory sequeal design, dimana data dari hasil wawancara akan membantu dan menjelaskan hasil data kuantitatif (Creswell, 2016; Teddie \& Tashakkori, 2009).

\section{Perubahan prilaku}

Perubahan prilaku dalam keluarga terjadi baik secara emosi maupun fisik. Perubahan aktivitas fisik terjadi karena adanya lockdown yang mengharuskan setiap individu harus tinggal di rumah dan membatasi aktivitas fisik (Morgül et al., 2020). Perubahan prilaku dalam praktik sebagai orang tua banyak berubah selama masa pandemic (Mazza et al., 2021; Romero et al., 2020; Shorer \& Leibovich, 2020; Spinelli et al., 2020; Yeasmin et al., 2020). Perubahan itu terjadi karena orang tua diharuskan mendampingi anak dalam belajar sekaligus harus mengerjakaan pekerjaan kantor dan rumah dalam waktu yang bersamaan (Morgül et al., 2020; Shorer \& Leibovich, 2020; Spinelli et al., 2020). Orang tua selama masa pandemic menjadi lebih koperaktif, terbuka kepada anak, dan interaksi kepada anak juga lebih baik (Mazza et al., 2021; Spinelli et al., 2020). Disamping perubahan prilaku pada orang tua, anak juga mengalami perubahan prilaku terlebih aktivitas sekolah yang harus dilaksanakan dirumah. Anak lebih punya banyak waktu untuk bermain daripada sebelum masa pandemic (Morgül et al., 2020; Romero et al., 2020; Yeasmin et al., 2020). Akantetapi ada perubahan negative selama masa pandemic COVID-19, anak mengalami perubahan perilaku untuk menggunakan elektronik lebih lama dengan alasan belajar (Morgül et al., 2020; Yue et al., 2020).

\section{Perubahan emosi dan Psikologis}

Selain terjadinya perubahan prilaku secara fisik pada orang tua dan anak, perubahan emosi dan psikologis juga terjadi dimasa pandemi COVID-19. Gangguan psikologis yang dialami yaitu gangguan kecemasan (Calvano et al., 2021; Gupta \& Jawanda, 2020; Li et al., 2021; Watamura \& Koppels, 2020;Orgilés et al., 2021;
Romero et al., 2020; Saurabh \& Ranjan, 2020; Yeasmin et al., 2020; Yue et al., 2020), stress ringan sampai berat (Morgül et al., 2020; Moscardino et al., 2021; Orgilés et al., 2021; Romero et al., 2020; Saurabh \& Ranjan, 2020; Shorer \& Leibovich, 2020; Spinelli et al., 2020; Calvano et al., 2021; Chartier et al., 2021; Cusinato et al., 2020), dan bahkan terjadinya depresi pada anak dan orang tua akibat proses karantina (Ma et al., 2021; Orgilés et al., 2021; Romero et al., 2020; Yeasmin et al., 2020; Yue et al., 2020; Watamura \& Koppels, 2020)). Selain itu, karena diperlakunya sistem karantina dan lockdown membuat orang tua maupun anak mengalami perubahan emosi berupa gangguan emosi yang mudah marah, tidak sabar dan susah dinasehati (Mazza et al., 2021; Morgül et al., 2020; Moscardino et al., 2021; Shorer \& Leibovich, 2020). Dampak lain dari karantina adalah risiko terjadinya Post Traumatic Sindrom (PTSD) (Ma et al., 2021; Yue et al., 2020). Menurut hasil penelitian Wulandari et al. (2020), perempuan hamil juga mengalami masalah psikologis karena takut untuk melakukan pemeriksaan ke layanan kesehatan. Fungsi emosi dan psikologis juga berdampak pada fungsi keluarga (Moscardino et al., 2021).

\section{Dampak masalah kesehatan jiwa}

Dampak dari masalah kesehatan jiwa akibat pandemi COVID-19 berupa masalah gangguan tidur (Watamura \& Koppels, 2020; Morgül et al., 2020; Yeasmin et al., 2020), penurunan kesejahteraan pada anak dan orang tua, serta tingkat kebahagian pada anak (Cusinato et al., 2020), meningkatnya kekerasan pada anak yang dilakukan oleh orang tua maupun anggota keluarga lainnya (Calvano et al., 2021; Cusinato et al., 2020; Watamura \& Koppels, 2020), dan kekerasan pada orang tua maupun pasangan (Calvano et al., 2021).

\section{SimPULAN DAN SARAN}

Pandemic COVID-19 memiliki dampak yang signifikan terhadap kesehatan mental bagi orang tua dan anak bahkan sampai mempengaruhi perubahan fungsi keluarga. Masala kesehatan mental selama masa pandemic harus diatasi dengan baik dan benar supaya tidak menimbulkan PTSD setelah masa pandemik selesai. Dari semua artikel yang didapat hampir semunya menggunakan penelitian kuantitatif sehingga peneliti menyarankan kepada peneliti selanjutkan untuk menggunakan metode kualitatif atau mixed metode. Jika ingin menggunakan metode peneliti menyarankan menggunakan design kuasi ekperimen yang 
bertujuan untuk mengatasi dan mencegah terjadi

\section{DAFTAR PUSTAKA}

Brooks, S. K., Webster, R. K., Smith, L. E., Woodland, L., Wessely, S., Greenberg, N., \& Rubin, G. J. (2020). The psychological impact of quarantine and how to reduce it: rapid review of the evidence. The Lancet, 395(14), 912-920.

https://doi.org/10.1016/S01406736(20)30460-8

Calvano, C., Engelke, L., Di Bella, J., Kindermann, J., Renneberg, B., \& Winter, S. M. (2021). Families in the COVID-19 pandemic: parental stress, parent mental health and the occurrence of adverse childhood experiences-results of a representative survey in Germany. European Child and Adolescent Psychiatry, (0123456789).

https://doi.org/10.1007/s00787-021-017390

Chartier, S., Delhalle, M., Baiverlin, A., \& Blavier, A. (2021). Parental peritraumatic distress and feelings of parental competence in relation to COVID-19 lockdown measures: What is the impact on children's peritraumatic distress? European Journal of Trauma and Dissociation, $5(2)$. https://doi.org/10.1016/j.ejtd.2020.100191

Creswell, J. (2016). Research design Pendekatan metode kuantatif, kualitatif, dan campuran (1st ed.). Yogyakarta: Pustaka Pelajar.

Cusinato, M., Iannattone, S., Spoto, A., Poli, M., Moretti, C., Gatta, M., \& Miscioscia, M. (2020). Stress, resilience, and well-being in Italian children and their parents during the COVID-19 pandemic. International Journal of Environmental Research and Public Health, 17(22), 1-17. https://doi.org/10.3390/ijerph17228297

Denney, A. S., \& Tewksbubry, R. (2013). How to Write a Literature Review. Journal of Criminal Justice Education, 24(3), 218234.

https://doi.org/https://doi.org/10.1080/1051 1253.2012.730617

Gupta, S., \& Jawanda, M. K. (2020). The impacts of COVID-19 on children. Acta Paediatrica, International Journal of Paediatrics, 109(11), 2181-2183. https://doi.org/10.1111/apa.15484

Hamzah, A. (2019). Metode Penelitian Kepustakaan (Library Research): Kajian Filosofis, Teoretis dan Aplikatif. Batu:
PTSD.

Literasi Nusantara.

Jiao, W. Y., Wang, L. N., Liu, J., Fang, S. F., Jiao, F. Y., Mantovani, M. P., \& Somekh, E. (2020). Behavioral and Emotional Disorders in Children during the COVID19 Epidemic. Europen Paediatric Association, 221(1), 264-266.

Kemenkes. (2020a). Pandemi COVID-19 Tuntut Masyarakat Hidup Normal yang Baru. Kemenkes. Retrieved from https://www.kemkes.go.id

Kemenkes. (2020b). Status Wabah Korona di Indonesia ditetapkan Sebagai Bencana Nasional. Retrieved from https://www.kemkes.go.id

Li, Y., Qin, L., Shi, Y., \& Han, J. (2021). The Psychological Symptoms of College Student in China during the Lockdown of COVID-19 Epidemic. Healthcare, 9(447), 1-9. $\quad$ https://doi.org/https:// doi.org/10.3390/healthcare9040447

Ma, Z., Idris, S., Zhang, Y., Zewen, L., Wali, A., Ji, Y., ... Baloch, Z. (2021). The impact of COVID-19 pandemic outbreak on education and mental health of Chinese children aged 7-15 years: an online survey. BMC Pediatrics, 21(1), 1-8. https://doi.org/10.1186/s12887-021-025501

Makarim, N. A. Pelaksanaan Kebijakan Pendidikan Dalam Masa Dadurat Penyebaran Coronavirus Disease (COVID19), Pub. L. No. Nomor 4 Tahun 2020 (2020). Indonesia: kemendikbud. Retrieved from https://www.kemdikbud.go.id

Masjoudi, M., Aslani, A., Khazaeian, S., \& Fathnezhad-kazemi, A. (2020). Explaining the experience of prenatal care and investigating the association between psychological factors with self-care in pregnant women during COVID-19 pandemic: a mixed method study protocol. Recenti Progressi in Medicina, 17(98), 1-7. https://doi.org/https://doi.org/10.1186/s129 78020009490

Mazza, C., Marchetti, D., Ricci, E., Fontanesi, L., Di Giandomenico, S., Verrocchio, M. C., \& Roma, P. (2021). The COVID-19 lockdown and psychological distress among Italian parents: Influence of parental role, parent personality, and child difficulties. International Journal of Psychology. https://doi.org/10.1002/ijop.12755

Morgül, E., Kallitsoglou, A., \& Essau, C. (2020). Psychological effects of the COVID-19 
lockdown on children and families in the UK. Revista de Psicología Clínica Con Niños y Adolescentes, 7(3), 42-48. https://doi.org/10.21134/rpcna.2020.mon.2 049

Moscardino, U., Dicataldo, R., Roch, M., Carbone, M., \& Mammarella, I. C. (2021). Parental stress during COVID-19: A brief report on the role of distance education and family resources in an Italian sample. Current Psychology, 10-13. https://doi.org/10.1007/s12144-021-014548

Orgilés, M., Espada, J. P., Delvecchio, E., Francisco, R., Mazzeschi, C., Pedro, M., \& Morales, A. (2021). Anxiety and depressive symptoms in children and adolescents during COVID-19 pandemic: A transcultural approach. Psicothema, 33(1), 125-130. https://doi.org/10.7334/psicothema2020.28 7

Page, M. J., McKenzie, J. E., Bossuyt, P. M., Boutron, I., Hoffmann, T. C., Mulrow, C. D., ... Moher, D. (2021a). The PRISMA 2020 statement: an updated guideline for reporting systematic reviews. Systematic Reviews, 10(89), 1-11. https://doi.org/10.1186/s13643-021-016264

Page, M. J., McKenzie, J. E., Bossuyt, P. M., Boutron, I., Hoffmann, T. C., Mulrow, C. D., ... Moher, D. (2021b). The PRISMA 2020 statement: an updated guideline for reporting systematic reviews. Journal of Clinical Epidemilogy, 19(26), 1-12. https://doi.org/10.1186/s13643-021-016264

Page, M. J., McKenzie, J. E., Bossuyt, P. M., Boutron, I., Hoffmann, T. C., Mulrow, C. D., ... Moher, D. (2021c). The PRISMA 2020 statement: an updated guideline for reporting systematic reviews. Plos Medicine, 18(3), 1-15. https://doi.org/10.1186/s13643-021-016264

Rias, Y. A., Rosyad, Y. S., Chipojola, R., Wiratama, B. S., Safitri, C. I., Weng, S. F., ... Tsai, H. T. (2020). Effects of Spirituality, Knowledge, Attitudes, and Practices toward Anxiety Regarding COVID-19 among the General Population in INDONESIA: A Cross-Sectional Study. Journal of Clinical Medicine, 9(12), 3798. https://doi.org/10.3390/jcm9123798

Romero, E., López-Romero, L., Domínguezálvarez, B., Villar, P., \& Gómez-Fraguela,
J. A. (2020). Testing the effects of covid19 confinement in spanish children: The role of parents' distress, emotional problems and specific parenting. International Journal of Environmental Research and Public Health, 17(19), 1-23. https://doi.org/10.3390/ijerph17196975

Saurabh, K., \& Ranjan, S. (2020). Compliance and Psychological Impact of Quarantine in Children and Adolescents due to Covid-19 Pandemic. Indian Journal of Pediatrics, 87(7), 532-536. https://doi.org/10.1007/s12098-020-033473

Shorer, M., \& Leibovich, L. (2020). Young children's emotional stress reactions during the COVID-19 outbreak and their associations with parental emotion regulation and parental playfulness. Early Child Development and Care, O(0), 1-11. https://doi.org/10.1080/03004430.2020.18 06830

Sitohang, T. R., Rosyad, Y. S., Widodo, A. K., Rias, Y. A., \& Malini, H. (2020). Perilaku Masyarakat Indonesia Bagian Barat Selama Pandemi COVID 19. Jurnal Kesehatan, 11(3), 356-359. https://doi.org/http://dx.doi.org/10.35730/j k.v11i3.775

Spinelli, M., Lionetti, F., Pastore, M., \& Fasolo, M. (2020). Parents' Stress and Children' $s$ Psychological Problems in Families Facing the COVID-19 Outbreak in. Frontiers in Psyhology, 11(July), 1-7. https://doi.org/10.3389/fpsyg.2020.01713

Sprang, G., \& Silman, M. (2013). Posttraumatic stress disorder in parents and youth after health-related disasters. Disaster Medicine and Public Health Preparedness, 7(1), 105-110.

https://doi.org/10.1017/dmp.2013.22

Sugiono. (2016). Metode Penelitian Kuantitatif, Kualitatif, dan $R \& D$ (23rd ed.). Bandung: Alvabeda.

Teddie, C., \& Tashakkori, A. (2009). Foundations of Mixed Methods Research: Integrating quantitative and Qualitative Approache in the Social and Behavioral Sciences (I). California: SAGE Publications.

Wang, G. H., Zhang, Y. T., Zhao, J., Zhang, J., \& Jiang, F. (2020). Mitigate the effects of home confinement on children during the COVID-19 outbreak. Journal of Shanghai Jiaotong University (Medical Science), 40(3), 279-281. https://doi.org/10.3969/j.issn.1674- 
8115.2020.03.001

Watamura, S. E., \& Koppels, T. (2020). Stress and parenting during the global COVID-19 pandemic. Child Abuse \& Neglect, 110(The COVID-19 Special Issue), 1-14. https://doi.org/https://doi.org/10.1016/j.chi abu.2020.104699

WHO. (2020). WHO Director-General's opening remarks at the Mission briefing on COVID-19. Retrieved March 30, 2021, from

https://www.who.int/dg/speeches/detail/\% 0Awho-director-general-s-statement-onihr-emergency-committee-onnovelcoronavirus-(\%0A2019)-ncov

Wulandari, S. R., Melina, F., Kuswanti, I., Rosyad, Y. S., \& Rias, Y. A. (2020). Respon Psikologi Perempuan Hamil Selama Masa Pandemi COVID-19. Jurnal Kesehatan, 11(Special Issue HKN (2020)), 257-260. https://doi.org/http://dx.doi.org/10.35730/j k.v11i0.742

Yeasmin, S., Banik, R., Hossain, S., Hossain, N., Mahumud, R., Salma, N., \& Hossain, M. M. (2020). Impact of COVID-19 pandemic on the mental health of children in Bangladesh: A cross-sectional study. Children and Youth Service Review, 117(105277), 1-7. https://doi.org/https://doi.org/10.1016/j.chil dyouth.2020.105277

Yue, J., Zang, X., Le, Y., \& An, Y. (2020). Anxiety, depression and PTSD among children and their parent during 2019 novel coronavirus disease (COVID-19) outbreak in China. Current Psychology, (2013). https://doi.org/10.1007/s12144020-01191-4

Zed, M. (2014). Metode Penelitian Kepustakaan (3rd ed.). Jakarta: Yayasan Pustaka Obor Indonesia. 